\title{
A New Framework for Production Planning and Control to Support the Positioning in Fields of Tension Created by Opposing Logistic Objectives
}

\author{
Matthias Schmidt, Philipp Schäfers \\ Institute of Production Systems and Logistics (IFA), Leibniz Universität Hannover, Hannover, Germany \\ Email: schaefers@ifa.uni-hannover.de
}

How to cite this paper: Schmidt, M. and Schäfers, P. (2017) A New Framework for Production Planning and Control to Support the Positioning in Fields of Tension Created by Opposing Logistic Objectives. Modern Economy, 8, 910-920.

https://doi.org/10.4236/me.2017.87064

Received: December 21, 2016

Accepted: July 18, 2017

Published: July 21, 2017

Copyright (๑) 2017 by authors and Scientific Research Publishing Inc. This work is licensed under the Creative Commons Attribution International License (CC BY 4.0). http://creativecommons.org/licenses/by/4.0/

\begin{abstract}
This paper presents an approach for modelling the connection between the tasks of production planning and control (PPC) and a supply chain's logistic objectives. Therefore a new production planning and control framework is developed. First of all, the tasks of production planning and control are described universally valid. A representation of a company's internal supply chain with five core processes complements the framework. For each core process, a system of logistic objectives is set up. The interdependencies between the variables presented in the systems are depicted. Existing fields of tensions between opposing logistic objectives are emphasized. For calculating values for PPC parameters and beyond that for positioning a production within the indicated fields of tension, existing quantitative logistic models are located in the framework. To clarify the overall approach the model-based calculation of lot sizes for production is presented exemplarily.
\end{abstract}

\section{Keywords}

Production Planning and Control, Supply Chain, Logistic Objectives, Modelling

\section{Introduction}

To begin with, the topic of research will be introduced. In the second step, the state of the art will be presented. Based on this, the need for research will be worked out. After that the structure and methodology of research will be introduced.

The topics of research are production planning and control and supply chain management. The mission of production planning and control is to plan the production concerning volumes and dates on a regular basis and to realize the 
plan despite unavoidable disruptions like delayed deliveries or the lack of staff as economically as possible [1]. In contrast, the mission of supply chain management is to plan and control the flow of material and information in supply chains or production networks aiming to satisfy the customer and to minimize costs [1].

Models can be used to represent logistic processes. Logistic models are superb tools to procure information and to support decision-making. Different types of logistic models can be distinguished. The two most important categories for the research presented in this paper are task and process models and quantitative descriptive, impact and decision-making models.

Task and process models are used to deliver references for designing tasks and processes in various areas. The Supply Chain Operations Reference Model (SCOR Model) [2] is a well-known instance. Focussing production planning and control the Aachen PPC model [3] has to be mentioned.

Other types of logistic model are quantitative descriptive, impact and decision-making models. They are referring to interactions of concrete variables, e.g. logistic objectives. The Logistic Operating Curve Theory [4] [5] is an example of a quantitative impact model. Using approximation equations, the Logistic Operation Curves make it possible to conduct a positioning of a production within the fields of tension created by the opposing logistic objectives work-in-process (WIP), throughput time and utilization. A positioning is required, because a minimization of WIP, a minimization of throughput time and a maximization of utilization cannot be realized at the same time. Numerous very good and very detailed quantitative logistic models do exist. They are applied in science and industry successfully. However, holistically designing PPC processes remains a challenge, because the individual models are not conjoined.

The mentioned perspectives of tasks and process models and quantitative descriptive, impact and decision-making models are combined by integrative logistic models. An established example is the manufacturing control model developed by LÖDDING [6]. It connects universally defined manufacturing control tasks with logistic objectives, control variables and actuating variables. The relation of certain aspects of the task and process models to objectives from the quantitative descriptive, impact or decision-making models is pointed out. For example, the task "release order" (from the Aachen PPC model [3]) is connected to the WIP (from the Logistic Operating Curves [4] [5]). Though, since the manufacturing control model has got a clear focus, the object being considered is restricted. While the control tasks are included, the planning tasks are mainly not. Furthermore the other core processes of a company's internal supply chain aside from production are not taken into account. This especially applies to procurement and dispatch.

To bridge this gap, the Hanoverian Supply Chain Model was developed. The approach of LÖDDING was extended in two ways: One the one hand vertically to additional PPC tasks and on the other hand horizontally to additional processes in a company's internal supply chain. 
Following, the methodology of research is introduced. To begin with, the rough structure of the model to be developed was defined. Several ideas were generated and one was selected. The decision was made, that there should be a PPC part and a supply chain part. After that the structure and the elements of both model parts were shaped in detail. For this reason, extensive reviews of literature were conducted. Relevant elements were selected in a systematic way.

\section{Composition of the Hanoverian Supply Chain Model}

Figure 1 shows the structure of the Hanoverian Supply Chain Model. The model consists of a PPC part (top) and a supply chain part (bottom). Both parts are connected. The fulfilment of the PPC tasks impacts the supply chain's logistic objectives.

The PPC part names the main and sub-tasks of production planning and control. The tasks are arranged in an approximate chronological and logical sequence. Terms and sequence used are based on pertinent literature [3] [7] [8]. The PPC main tasks are: Plan Production Program, Manage Order, Dispatch Order, Plan Secondary Requirements, Roughly Plan Sourcing, Plan Sourcing, Plan Production Requirements, Plan Production, Control Production, Monitor Production and Manage Inventory. For each main task there is an individual representation with further details. These representations contain several subtasks belonging to the main tasks. For each sub-task also the incoming and outgoing information is indicated. Moreover iteration loops within one main task or between different main tasks are pictured.

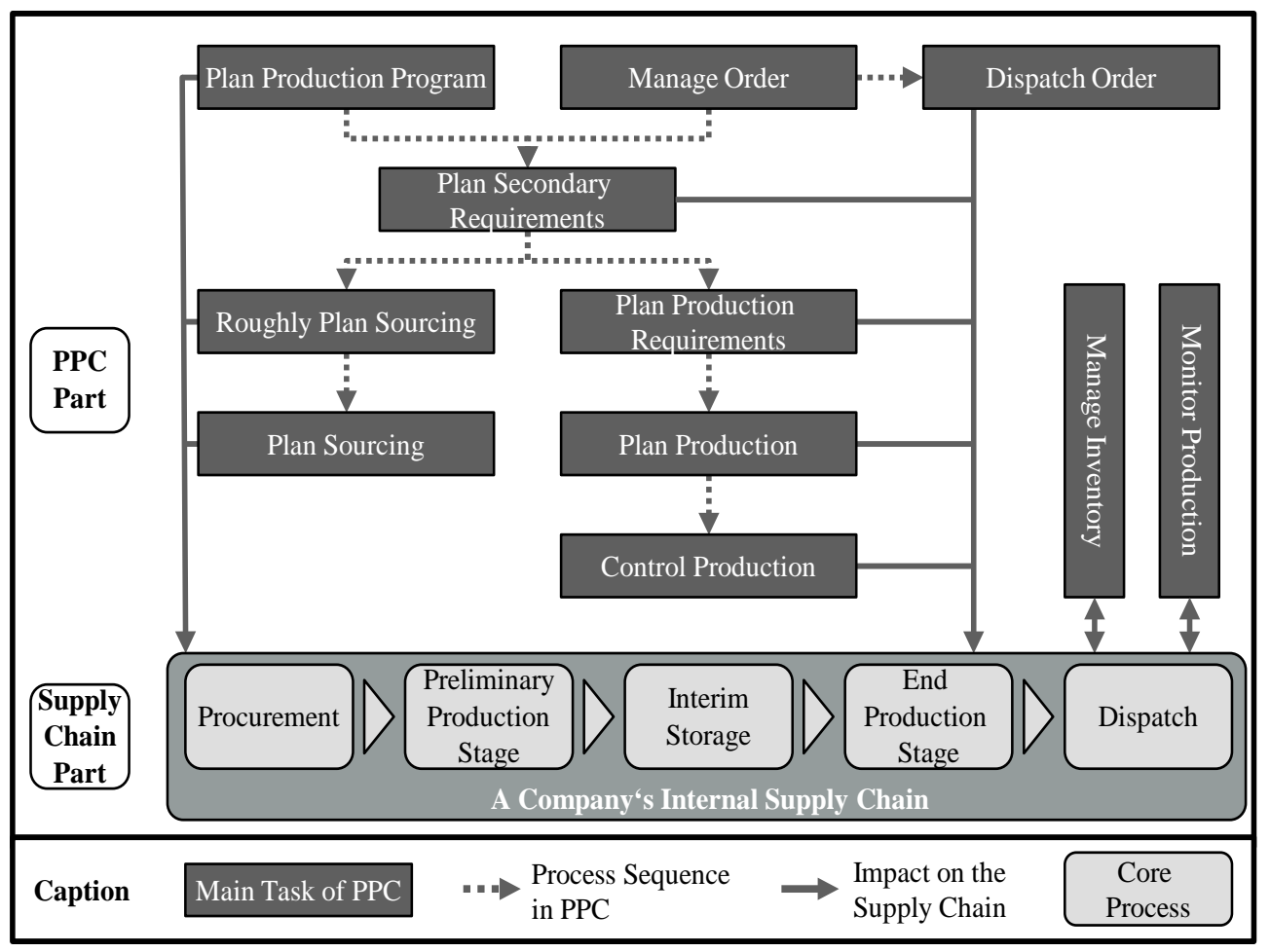

Figure 1. Structure of the Hanoverian Supply Chain Model consisting of two parts: PPC part (top) and supply chain part (bottom). 
The supply chain part depicts a company's internal supply chain and features the most important logistic objectives. The structuring of the supply chain part is based on the structuring of the SCOR Model [2]. Looking at PPC, it is crucial whether a production deals with primary or secondary requirements. Having this in mind, the structuring of the SCOR Model was refined. The five core processes procurement, preliminary production stage, interim storage, end production stage and dispatch can be used to describe a company's internal supply chain. The supply chain part of the model has got a focus on the relation between the target, planned and actual variables in the material flow within a supply chain and consequently the impact on the logistic objectives. The objectives are specific for each core process mentioned. Therefore for each core process a system of logistic objectives, control variables and actuating variables was established following the approach of LÖDDING [6].

\section{Setting up Systems of Logistic Objectives}

In the five core processes of a company's internal supply chain many elements do have an impact on the logistic objectives. To set up systems following the schema developed by LÖDDING [6] two steps were performed. Firstly, the relevant logistic objectives for each of the five core processes of a company's internal supply chain were identified. To reach this goal an extensive literature review was performed to collect KPIs (a. o. [9]) followed by a selection of the most important ones. Based on the now available logistic objectives, actuating variables and control variables were derived. Looking at the definition an actuating variable is affected by PPC respectively a PPC task. On the contrary control variables result from the discrepancy of two actuating variables and directly impact the logistic objectives.

Looking at the core processes of a company's internal supply chain the inputs and outputs of materials or orders are very important. For each input and each output there are planned values and actual values. In the core process dispatch you can also find a target value for the output to the customer. By fulfilling the tasks of PPC the inputs and the outputs are planned and controlled. The de facto measured inputs and outputs lead to the actual inputs and outputs of the core processes. That is why the inputs and the outputs are the actuating variables. The actuating variables affect the control variables. For all core processes the stores respectively the WIP is a control variable. The stores in the system can be calculated easily examining the inputs and the outputs. For some core processes the due date behaviour on the output side is another control variable. The quantitative backlog and the lateness of the orders can be diagnosed contrasting the actual values with the planned values. The control variables have got a direct impact on the core process specific logistic objectives. As it becomes apparent the logistic objectives are determined by the PPC tasks via the actuating variables and control variables.

To give an example, Figure 2 shows the system developed for the core process end production stage. Schedule reliability, throughput time, utilization and 


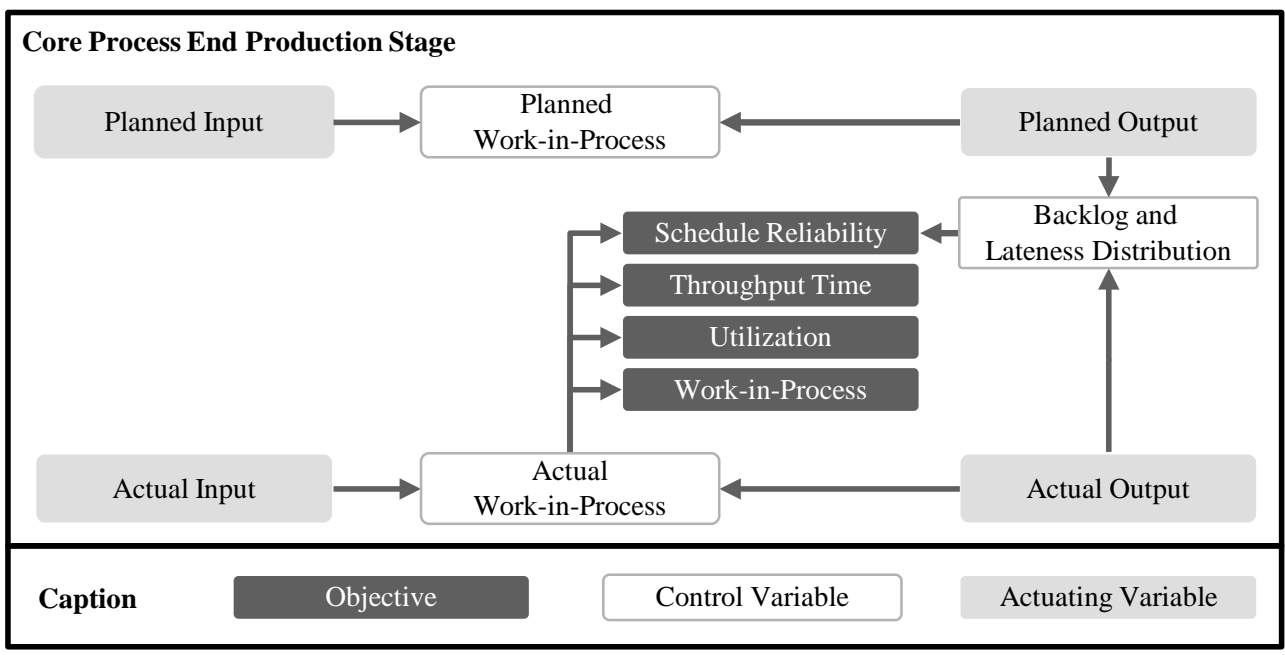

Figure 2. System of logisctic objectives for the core process end production stage (based on [6]).

work-in-process were identified as logistic objectives for this core process. As stated before, actuating variables (inputs and outputs) and control variables impact the logistic objectives. In the core process end production stage the workin-process is the first control variable. The actual WIP results from the difference between the actual inputs and the actual outputs. Thus, the actual WIP is the stock of approved orders within the end production stage. The backlog and the distribution of lateness of the output in the end production stage process is the second control variable. It results from the difference between the planned and the actual output.

It is important to know, that some of the logistic objectives within core processes or across core processes are opposing. While fulfilling the tasks of PPC companies have to deal with these conflicts of objectives. Fields of tension arise. These are illustrated and discussed in the Hanoverian Supply Chain Model. Subsequently, one such conflict is described as an example. To be consistent, again the core process end production stage is focussed.

The utilization describes the ratio from actual performance to highest possible performance of a workstation or a production area. For an economic use, the utilization should be as high as possible. Thus, the WIP must be on an appropriate high level, so that the flow of material is not interrupted and the resources are used to capacity. But more aspects must be considered when defining the WIP in production. Firstly, with a high WIP capital costs and handling costs rise. Secondly, a high WIP causes long waiting times at workstations and thus longer throughput times for the production orders. Because of the increasing throughput times and the accompanying increasing scatter of throughput time, the lateness distribution and the schedule reliability are affected negatively.

As the example shows, there are conflicts between the logistic objectives. Producing companies must position themselves within the fields of tension arising. For this, the different objectives have to be evaluated and each company has to prioritize the objectives according to their corporate goals. Moreover, the entire PPC processes and parameters have to be oriented towards the chosen objec- 
tives. Thus, a profound understanding of the interactions between the PPC tasks and logistic objectives is required to perform a conscious positioning.

\section{Interactions between PPC and the Logistic Objectives}

For the success of a company it is fundamental to understand how the decisions in production planning and control affect the actuating variables and control variables and via these the logistic objectives of the supply chain. That is why the Hanoverian Supply Chain Model contains further levels to detail the processes and interactions in the PPC main tasks. Figure 3 shows the representation for the PPC main task "plan production". There is an equivalent representation for all other main tasks of PPC (see Figure 1).

By performing the PPC main task "plan production" specific production orders are created based on the in house production program resulting from the prior PPC main task "plan production requirements". At first, a lot size calculation is performed and the economically optimal production volume is determined. Next, the start and end dates of individual operations within the production orders are defined. The throughput of production orders is scheduled. Then, the availability of the required resources is examined and a detailed resource allocation plan is worked out. Together, the created production orders with due dates and amounts lead to the production plan. Now the feasibility of the production plan has to be checked. If the production plan cannot be implemented, the resulting information from prior PPC main tasks (e.g. the in house production program from PPC main task "plan production requirements") have to be questioned. As soon as the production plan is regarded as feasible, it may

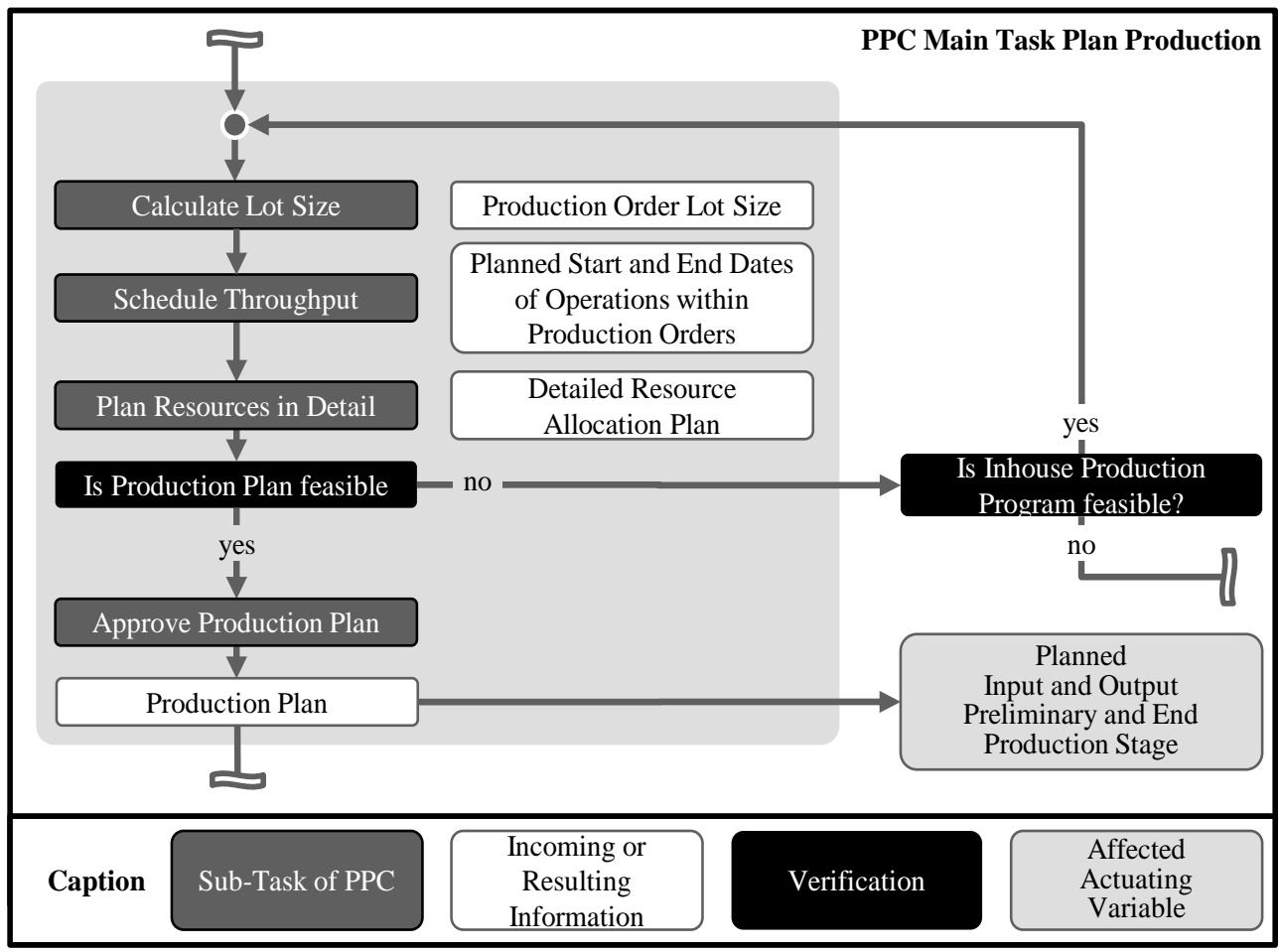

Figure 3. PPC Main Task Plan Production. 
be approved. Main result of the PPC main task "plan production" is the released production plan, containing short-term and medium-term production orders. In the process sequence of PPC the production plan is passed on to the PPC main tasks "control production" and "mange inventory" for implementation. Considering the systems of logistic objectives presented in section 3 the production plan determines the planned input and the planed output of the preliminary production stage and the end production stage.

\section{Locating Quantitative Logistic Models in the Framework}

The Hanoverian Supply Chain Model is developed to serve as a framework for PPC and a company's internal supply chain. It clarifies the interactions between the tasks of production planning and control, the actuating variables, the control variables and the logistic objectives in core processes. Existing conflicts between logistic objectives are discussed. Like that the decisions within the PPC tasks can be taken with clarity about the interactions and the consequences. Moreover, existing quantitative logistic models are included in the framework. These models can be used to calculate values for PPC parameters. Furthermore a positioning within the indicated fields of tension created by logistic objectives can be performed.

To exemplify the approach to use quantitative logistic models to support the fulfilment of the PPC tasks we will have a closer look at the calculation of lot sizes. This is a sub-task of the PPC main task "plan production" (see Figure 3). The aim of this task is to calculate the economically optimal lot size. Concentrating on a make-to-stock production a field of tension between setup costs, storage costs and logistic performance arises. The bigger the lot size, the less often workstations have to be changed and the smaller are the setup costs. On the other side, big lots lead to high inventory in following storages and the logistic performance of the production is influenced negatively.

Setup costs result from the changes of production facilities between producing two different lots. The setup costs incur for each adjustment. Therefore, the setup costs increase when reducing the lot size. Normally, the setup costs comprise of material and wage costs for cleaning the production facility, wage costs for adjusting the production facility and assembling special components, tool change costs, transport costs, machine costs during the setup time, start-up costs and administrative expenses for the creation of production orders [10].

In contrast, the higher the lot size, the higher will be the storage costs, because more products will be stored. There are interest costs for fixed capital. Moreover costs for the care of the stored products arise. In addition, risk cost, for example for the loss of value, may occur. And there are depreciation costs, insurance costs and maintenance costs for the buildings and the technology of the storages [10].

Besides the addressed setup costs and storage costs, the lot size has got a big impact on the logistic performance of a producing company. There is an effect on the throughput time, the distribution of the throughput time, the distribution 
of lateness of production orders, the safety stock level in the storage for finished goods to compensate poor logistic performance and the flexibility of production [10].

To calculate the lot size, different methods may be used. Most of them focus the costs. A distinction is made between static and dynamic methods. Static approaches determine one lot size value for each item. This lot size is implemented as a fixed value into the PPC system for a certain period of time. As the underlying parameters may change the value must be verified regularly. In contrast, dynamic approaches define a new lot size for each production order, depending on the current conditions.

The opposing effect of the setup costs and storage costs implies that a cost-optimal solution exists for calculating the lot size. Using the traditional approach by HARRIS the optimal lot size is determined based on these two elements (setup costs and storage costs) [11]. MÜNZBERG extended this method and provides a logistic model to determine the optimal lot size based on more costs [12] [13]. The model considers the impact of the lot size on the logistic performance. The logistic objectives like work-in-process, throughput time and schedule reliability are transformed into costs. A logistic costs factor is implemented. Figure 4 shows the basic idea of the approach and the optimal lot sizes according to HARRIS and MÜNZBERG. Taking the logistic performance into consideration the calculation leads to significantly smaller lot sizes.

It becomes obvious, that the lot size is a parameter of PPC, evoking a company to make a decision. The determination of the parameter takes place in a

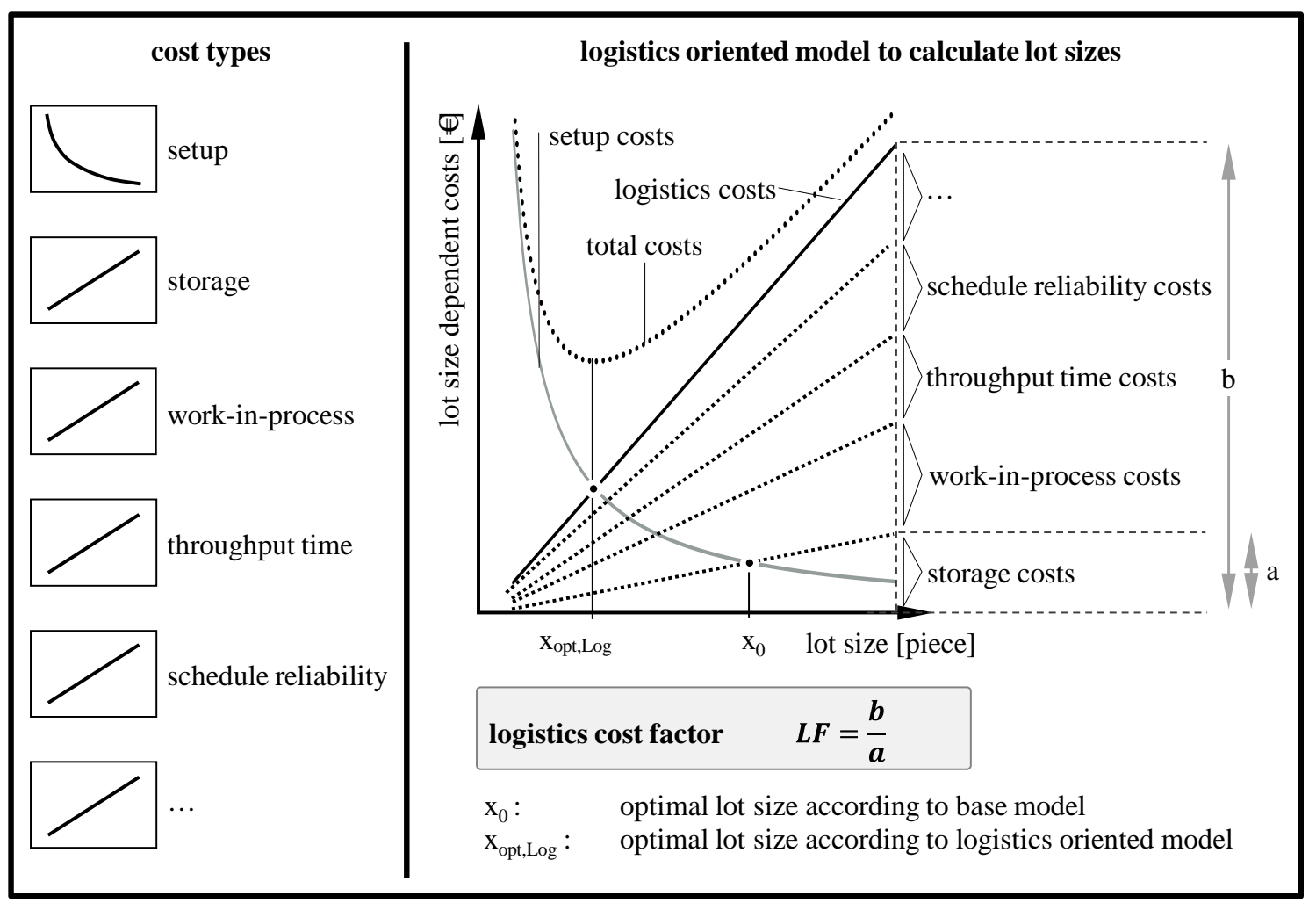

Figure 4. Logistics oriented model to calculate lot sizes and included cost types [12]. 
stress field of logistic objectives. By defining a value for the parameter lot size a positioning takes places. The presented logistic model developed by MÜNZBERG can be used to perform this positioning. The framework Hanoverian Supply Chain Model discloses which models should be used in a certain case. By locating the quantitative logistic models within the framework, the partial models are combined into a unified context.

\section{Future Research}

More research could be conducted in future to extend the Hanoverian Supply Chain Model. There are several ideas.

The first idea addresses the topic of Industry 4.0. New technologies arise and are applied in production systems. Resulting from the increasing digitilaziation more and better data will be present in production systems. The technologies and the data can be used to enhance production planning and control. Research is needed to investigate, in which way production planning and control will change because of Industry 4.0.

Another idea addresses product return and circular material flow. There are new laws and standards concerning product return in Europe. Generally, material efficiency becomes more and more important for producing companies. To represent these trends a reverse supply chain could be added to the Hanoverian Supply Chain Model. There could be research about the consequences of a reverse supply chain for SCM and PPC.

\section{Conclusion}

A new framework for PPC and SCM-named the Hanoverian Supply Chain Model-is introduced. It was developed at the Institute of Production Systems and Logistics of Leibniz Universität Hannover in Germany. Firstly, the model provides a universally valid description of the tasks of production planning and control. In this way, profound knowledge about PPC is provided in a comprehensible way. The process descriptions can actually be used by companies to design or improve processes. Secondly, systems of logistic objectives are defined for five core processes (procurement, preliminary productions stage, interim storage, end production stage, dispatch) that represent a company's internal supply chain. These systems include the relevant logistic variables for each core process. Moreover, the influence of the PPC tasks on the systems is pictured. The systems show the relevant relations at a glance. Thirdly, existing fields of tension between logistic objectives are fore grounded. These fields of tension have to be considered while fulfilling the PPC tasks. Quantitative logistic models can be used to compute values for PPC parameters and moreover to position a production within the indicated fields of tension. These partial models were located within the framework Hanoverian Supply Chain Model. Like this, companies can use the partial models to design specific elements of their production systems or to fulfill specific tasks of PPC according to strategic goals. The main achievement respectively main contribution to research of the Hanoverian 
Supply Chain Model is the integrated consideration of PPC and a supply chain. The interactions between the PPC tasks and the logistic objectives alongside a supply chain are pointed out. The model supports companies to design and conduct production planning and control in-line with strategic goals.

\section{Acknowledgements}

This paper presents results of the project "Integrative Logistics Model for Linking Planning and Control Tasks with Logistical Target and Control Variables of the Company's Internal Supply Chain" (SCHM-2624/4-1), funded by the German Research Foundation (DFG) and currently being conducted at the Institute of Production Systems and Logistics.

\section{References}

[1] Wiendahl, H.-P. (2014) Betriebsorganisation für Ingenieure, 8th Edition. Hanser, München.

[2] Supply Chain Council (2010) Supply Chain Operations Reference Model. Rev. 10.0. Supply Chain Council Inc., Cypress.

[3] Schuh, G. (2006) Produktionsplanung und -steuerung-Grundlagen, Gestaltung und Konzepte. 3rd Edition, Springer, Heidelberg. https://doi.org/10.1007/3-540-33855-1

[4] Nyhuis, P. (2006) Logistic Production Operating Curves-Basic Model of the Theory of Logistic Operating Curves. CIRP Annals-Manufacturing Technology, 55, 441-444. https://doi.org/10.1016/S0007-8506(07)60454-5

[5] Nyhuis, P. (2007) Practical Applications of Logistic Operating Curves. CIRP Annals-Manufacturing Technology, 56, 483-486. https://doi.org/10.1016/j.cirp.2007.05.115

[6] Lödding, H. (2013) Handbook of Manufacturing Control-Fundamentals, Description, Configuration. Springer, Heidelberg.

https://doi.org/10.1007/978-3-642-24458-2

[7] Orlicky, J. (1975) Material Requirements Planning - The New Way of Life in Production and Inventory Management. McGraw-Hill, New York.

[8] Wight, O. (1984) Manufacturing Resource Planning-MRP II-Unlocking America's Productivity Potential. Rev. Edition. Wight, Essex Junction.

[9] Hon, K.K.B. (2005) Performance and Evaluation of Manufacturing Systems. CIRP Annals-Manufacturing Technology, 54, 675-690. https://doi.org/10.1016/s0007-8506(07)60023-7

[10] Nyhuis, P., Münzberg, B. and Schmidt, M. (2011) Discussion of Lot Sizing Approaches and Their Influence on Economic Production. Proceedings of the 21 st International Conference on Production Research.

[11] Harris, F.W. (1913) How Many Parts to Make at Once. Factory-The Magazine of Management, 10, 135-136.

[12] Münzberg, B. (2013) Multikriterielle Losgrößenbildung. TEWISS-Technik und Wissen $\mathrm{GmbH}$, Garbsen.

[13] Schmidt, M., Münzberg, B. and Nyhuis, P. (2015) Determing Lot Sizes in Production Areas-Exact Calculation versus Research Based Estimation. Procedia CIRP, 28, 143-148. https://doi.org/10.1016/j.procir.2015.04.024 


\section{Appendix}

The Hanoverian Supply Chain Model is published on an interactive website. The English version is provided at http://www.hasupmo.education/, whereas the German version is provided at http://www.halimo.education/. Beside the top level of the model the web site provides profiles with definitions and further information of the PPC tasks and the logistic objectives. Because the web site is freely accessible on the internet, it is an interesting tool for scientists, students and companies, who are active in the fields of PPC and SCM.

Submit or recommend next manuscript to SCIRP and we will provide best service for you:

Accepting pre-submission inquiries through Email, Facebook, LinkedIn, Twitter, etc. A wide selection of journals (inclusive of 9 subjects, more than 200 journals)

Providing 24-hour high-quality service

User-friendly online submission system

Fair and swift peer-review system

Efficient typesetting and proofreading procedure

Display of the result of downloads and visits, as well as the number of cited articles Maximum dissemination of your research work

Submit your manuscript at: http://papersubmission.scirp.org/

Or contact me@scirp.org 